Printed Version: (ISSN 2090-5262)

Online Version: (ISSN 2090-5270)

July 2012, Volume 2, No. 2 Pages (93 - 104)

\title{
Start Anxiety State and Its Relationship to Some Physiological Changes and the Concentration Level of Norepinephrine Hormone in the Blood of Karate Players
}

\author{
Hala Moustafa Ibrahim Gomaa*
}

\begin{abstract}
:
This study aims at identifying the relationship between the start anxiety state and some physiological variables (pulse rate per minute - breath rate per minute) and the concentration level of the Norepinephrine hormone in the blood of some karate players. The descriptive method was used. The study was conducted on an intentional samples of karate players participating in the university karate competition 2009/2010. The sample included 6 players. The modified version of the competitive state anxiety Inventory-2 (Martens et al.) (CSAI-2) was utilized. The physiological measurements included measuring the pulse rate per minute, the breath rate per minute and the concentration level of Norepinephrine hormone in blood. The first measurement was conducted 3 weeks before the competition whereas the second, was conducted 1 hour before the first match. Results were (1) There was an increase in the intensity of cognitive and somatic anxiety of karate players 1 hour before the competition, and a decrease of cognitive, somatic anxiety directions 1 hour before competition; (2) There was an increase in the breath rate, pulse rate and the Norepinephrine hormone secretion in blood 1 hour before competition, with the amount released twice as high as in the normal condition 3 weeks before competition; (3) There was no relationship between the dimensions of the competitive state anxiety and the physiological variables and the rate of the Norepinephrine hormone secretion in blood. The important conclusions were (1) Selfconfidence of karate players decreased 1 hour before competition (2) Intensity of cognitive anxiety was higher than intensity of physical anxiety in karate players 1 hour before competition.
\end{abstract}

\section{Introduction:}

$\mathrm{P}$ sychological phenomena in the field of sport and the accompanying physiological and chemical variables in the athlete's body are vital topics in sport psychology for the indications they give about the psychological and physiological state of athletes.

The start anxiety state is one of the most important psychological phenomena encountered by athletes in competitions and associated situations, events and stimuli that may have clear effects on the player's sports performance and on his abilities, skills and relations with others. ( $12: 397)$

Osama Rateb (2000) confirms that anxiety at the beginning of competition is one of the

\footnotetext{
* Assistant Professor, Department of Educational, Psychological and Social Sciences, Faculty of Physical Education for Girls, Alexandria University, Egypt.
}

psychological problems that face athletes before competitions for the negative effects it has on their performance, such as wasting their physical energy and poor self-confidence, or being overwhelmed by a feeling of inefficiency. (3: 271).

According to Abdul Aziz Salama (2001), start anxiety state is a normal phenomenon that all athletes go through. The basic function of such a state is to take the player from the state of negative waiting to actual participation. In addition, it significantly contributes to preparing the player for the effort he is expected to exert in the competition. Sometimes, however, the phenomenon has some negative, unpleasant effects that lead to a drop in the player's ability and performance level during sports events. Thus, the level of anxiety at the beginning of competition with its psychological and physiological aspects may have a positive or a negative effect, since too much or too little 
anxiety would have a negative effect as a result of stimulating the nervous system which would, in turn, cause physiological and biochemical changes, thus creating a state of imbalance between physical and psychological powers. (15:122, 205).

Ahmed Amin (2003) states that over - anxiety leads to confusing or hindering sport performance, while too little anxiety leads to a state of indifference when athletes encountered by actual situations. In both cases, anxiety is considered a negative factor in the competitive sports situation. Conversely, an 'appropriate' level of anxiety, would help athletes to produce the desired performance and to face the competitive situation and overcome it, thus, turning into a positive factor. (1:243).

Anxiety includes emotional, cognitive and physiological components. Whereas the emotional component of anxiety is represented in feelings of fear and tension, the cognitive component is translated in the negative effects of these feelings on the person's perception of the competitive situation, attention, concentration, memorizing, and problem solution The physiological component is demonstrated in the consequences of the state of anxiety, namely stimulating and activating the self-nervous system. This usually leads to several physiological changes such as the increase in pulse rate and fast breathing. $(2: 121$, 122).

Multi-dimensional anxiety is a relatively recent theory in so far as athletes are concerned. Anxiety is here classified into cognitive anxiety, somatic anxiety and self confidence. Application of the theory showed that cognitive anxiety and somatic anxiety must be distinguished from each other, as each has different symptoms.( 12:400)

Ahmed Amin (2003), suggests that before competition anxiety symptoms may be more apparent on the cognitive level in some athletes, and on the somatic level in others, and still on the emotional level in other athletes. This depends on the person's nature. Here, lies the importance of the theory of multi-dimensional anxiety in using particular approaches and means to face the anxiety dimension that the player shows.(1:248)
Mahmoud Anan (1995), suggests that the physiological and biochemical changes help identify sports competition anxiety through the direct measuring of the concentration of Norepinephrine hormone in the blood and by using blood samples directly. This can be a reliable method that gives a true evidence on the level of anxiety level in the player. It can be an indication for the physiological changes, too. $(16: 269)$

Bahaa Eddin Salama (1990), states that the physiological and biochemical changes can not be separated when studying any life phenomenon in the organism, whether at rest or during sports training or competition. Both types of change should be known, as they mutually affect each other. Identifying the chemical changes that have taken place in the body helps identify the physiological changes and the reasons why they occur.(4:5)

The nervous system works with the endocrine system in organizing and coordinating all the body's physiological and biochemical activities. There is an essential relationship between the two systems. many hormones are secreted by stimulating the neurons, and the central nervous system, performs a self-organizing process using the endocrine system because hormones affect the composition of proteins and the enzymatic activities in the tissues forming the brain. ( 13:1) $(18: 22)$

Abdul Mottaleb El-Quraity (1998), suggests that hormones work as internal stimuli because their secretions contribute to determining the behavioral results. An imbalance in adenoid activities whether they increase or decrease, leads to imbalance of a person's general activity; and disorder of his emotional and mental abilities.(7:169)

The Adrenal Glands (suprarenal glands) are important because of their secretions which are closely connected to emotional behaviour.(6:29). Secretory disorders lead to several physiological and psychological disorders: hyperhormonism increases pulse rate and leads to rapid breathing, hypertension and anxiety, whereas hypohormonism leads to decrease of pulse rate, inactivity and emotional indifference.(7:201, 202) 
The internal part of the Adrenal Medulla releases two hormones: Epinephrine or Adrenaline, and Norepinephrine or Noredrenaline. These are called, Catecholamines. Both play an important biological role in the human body especially in response to stress and quick arousal and It is also called the emergency hormones..(14:186) $(23: 692$ )

Major characteristics of the Norepinephrine hormone include increase of the pulse rate, increase in diastolic blood pressure, increase of muscle fibers susceptibility to arousal and constriction of blood vessels of limbs. Measuring the concentration level of this hormone in the blood of karate was used to identify their state of anxiety before competition. (5: 176)

Mahmoud Saad(2001), suggests that individual combative games have a nature of their own because of the physical contact and direct fight between the two players. Each tries to subject the other's body to his will, and spoil his goals, according to the international rules governing each type of combat. So, a player should exploit all his physical and psychological power to win in the competition. $(17: 3)$

\section{Importance of the Research:}

This paper derives its chief significance from the fact that the start anxiety state is one of the major problems encountered by athletes. Consequently, identifying such a state is of paramount importance, since too much or too little sport anxiety has a number of negative effects, such as poor performance, lack of selfconfidence and a decline in the ability to correctly assess the opponent's attitude, and to solve the problem. Anxiety occurs as a result of stimulating the nervous system, leading to physiological and biochemical changes which are inseparable and mutually effective.. it is through biochemical changes that we come to know about physiological changes and their causes. In this paper a number of physiological changes were used as indicators of the start anxiety state, including pulse rate and breath rate. Pulse rate was used because the heart is one of the organs most affected by excitement, and the number of pulse rate changes according to the type of excitement, besides, measuring pulse rate can easily be done. There is also a strong relationship between the pulse rate and the breath rate.

The Norepinephrine hormone (also known as the 'emergency hormone') was chosen as an indicator of the start anxiety state because it is closely connected to the emotional behaviour of the athlete. Any increase or decrease in the Norepinephrine hormone would lead to physiological, mental and emotional disorders that would negatively affect the behaviour of the athlete during competition. In this paper, the above- mentioned measurements were applied to karate players, bearing in mind that this particular sport is gaining ground in Egypt, yet not sufficiently studied from the psychological point of view. It is the karate player who takes the whole responsibility, and is responsible for the combating, for his behavior and for the result of competition. So, he is in a state of anxiety for fear of failure, and of losing the social prestige associated with winning the competition.

A review of scientific literature on the subject in Arab countries showed that measuring the start anxiety state has so far counted on pen and paper tests that yielded unobjective results, depending on the credibility of the person examined when answering the test questions. Such tests can not, therefore, be considered an indicator of the athlete's state of anxiety. Instead, the present study attempted to use the physiological or biochemical measurements study the state of start anxiety and its relationship to the physiological changes and the concentration level of Norepinephrine hormone in the blood of karate players.

\section{Objectives of the Research:}

1. Identifying the differences between the first measurement ( 3 weeks before the competition); and the second measurement ( 1 hour before the first match) in karate players in the dimensions of the start anxiety state (intensity - direction) and the physiological changes (pulse rate breath rate) and the concentration level of Norepinephrine hormone in blood .

2. Identifying the relationship between the start anxiety state dimensions and the physiological 
changes (pulse rate - breath rate) and the concentration level of Norepinephrine hormone in blood in karate players.

\section{Research Hypotheses:}

1. There are statistically significant differences between the first measurement ( 3 weeks before the competition); and the second measurement ( 1 hour before the first match) in karate players in the dimensions of the start anxiety state (intensity - direction) and the physiological changes (pulse rate - breath rate) and the concentration level of Norepinephrine hormone in blood .

2. There is a relationship between the dimensions of the start anxiety state (intensity direction ) and the physiological changes (pulse rate - breath rate) and the concentration level of Norepinephrine hormone in blood 1 hour before the first match.

\section{Research Procedures:}

\section{Methodology:}

The descriptive method was used in the study, being suitable for this type of research.

\section{Research Sample:}

The sample was intentionally selected among karate players (kumite) participating in the university karate championship of the faculty of physical education for boys, in Abu Qir, held in Ibrahim Moustafa Hall, Alexandria Stadium in the academic year 2009/2010. The players were six in number, in addition to 18 players who were not from the basic research sample in the exploratory study. Conducting the research on a large number of karate players was made difficult by: 1) the refusal expressed by many players to allow blood sample to be taken from them, and 2) the high cost of chemicals used in analyzing the norepinephrine hormone.

Criteria for selecting the sample:

1. The training age of all subjects of the research sample should not be less than five years.

2. Players should be healthy.

3. Players must be winners of the republic championship of karate.

The author calculated the arithmetic mean, the standard deviation and the coefficient of skewness of the primary research variables data (age - height - weight - years of practice) to prove the moderation of the data for the basic sample subjects in these variables, as shown in table (1).

Table (1)

Arithmetic mean, standard deviation and coefficient of skewness of the research sample data in the primary variables $(N=6)$

\begin{tabular}{|c|c|c|c|c|c|c|}
\hline \multirow{2}{*}{ Variables } & \multirow{2}{*}{$\mathbf{N}$} & \multicolumn{5}{|c|}{ Descriptive Statistics } \\
\cline { 3 - 7 } & & Mean & Median & $\begin{array}{c}\text { Std. Error of } \\
\text { Mean }\end{array}$ & $\begin{array}{c}\text { Std. } \\
\text { Deviation }\end{array}$ & Skewness \\
\hline Age & 6 & 21.436 & 21.68 & 0.451 & 1.562 & -0.463 \\
\hline Height & 6 & 172.363 & 172.81 & 0.889 & 3.078 & 0.018 \\
\hline Weight & 6 & 72.983 & 73.39 & 1.384 & 4.795 & 0.036 \\
\hline $\begin{array}{l}\text { Years of } \\
\text { practice }\end{array}$ & 6 & 8.438 & 9 & 0.346 & 0.980 & -0.833 \\
\hline
\end{tabular}

Table (1) shows that the coefficient of skewness in the primary research measurements ranges from

0.036 to 0.833 i.e. it falls within $( \pm 3)$ and is near to zero. This proves the homogeneity of the research sample in these variables.

Measurements and Tools Used in Research: Following a review of Arab and international references and previous studies on sport competition anxiety and the physiological and biochemical variables with the measurements designed to measure them, the main variables and measurements of the present study were determined as follows:

\section{Basic Measurements: Height and Weight:}

A restameter was used to measure height, to the nearest centimeter. To measure weight, a 
medical scale was used that gives records to the nearest $100 \mathrm{gm}$.

\section{Measuring the start anxiety state:}

The modified version of the competition State anxiety Inventory (CSAI - 2) designed by Martens, Burton, Vealy, Bumb and Smith, which was Arabized by Mohammed Hassan Allawy (1998), was used. This version measures the intensity and direction of each of the inventory dimensions: cognitive anxiety, somatic anxiety and self-confidence. It is applied under the title "the modified version of the directions inventory towards a sports game, because this would reduce the bias in the subjects' response. The inventory includes 27 statements, at the rate of 9 statements for each dimension, in which each subject is asked to express how he feels during a specific period before competition. This period is specified by the researcher on a four-degree-scale that measures intensity; and on another sevendegree-scale, ranging from 'very retarding' (at degree 1) to 'very helpful' at degree (7) to measure the direction of anxiety [Attachment 1] (11: 250,259$)$

\section{Physiological Measurements:}

Pulse Rate per Minute: An electronic blood pressure equipment was used that does not require special skills to operate.

Breath Rate: this was measured by putting the hand at the middle of the player's chest and counting the number of the times the chest rise up per minute using a stop watch.

\section{Measuring the level of Norepinephrine hormone in blood:}

Blood samples were taken by a laboratory technician and put in special blood collecting tubes closed with plastic stoppers. Samples were kept in fridges at $4-8^{\circ} \mathrm{C}$ during the measurement period before the competition until they were taken to the laboratory for analysis.

The following devices and tools were used in measuring the Norepinephrine hormone:

- Test tubes to keep blood samples.

- Plastic tubes to keep the blazma.

- Medical materials (cotton- antiseptic).

- Hand fridge to keep blood samples.

- $5 \mathrm{~cm}$ - syringes to take blood samples.
- A $3000 \mathrm{rpm}$ (revolutions per minute) Centrifuge system to separate serum.

- Enzyme Linked Immuno Sorbant Assay (Elisa) to measure the concentration of Norepinephrine hormone in blood.

- To record these measurements, a form was designed where the data of each player was recorded in the first measurement and 1 hour before competition.

\section{Pilot Study:}

The pilot study was conducted on Tuesday $29 / 09 / 2009$ on a sample of 18 karate players who were not subjects of the basic research sample, to determine the scientific coefficients (validity - reliability) of the competition anxiety inventory.

\section{Validity Coefficient}

In order to make sure of the validity of the sport competition anxiety inventory, the internal consistency method was used by calculating the coefficients between the score given to each statement and the total scores of the intensity and direction of the dimension of the statement in the inventory [Attachment 2]. The correlation coefficients between the intensity of each of the cognitive dimension statements and the total score of the intensity of the cognitive dimension ranged from 0.656 to 0.852 . The correlation coefficients between the intensity of each of the somatic dimension statements and the total score of the intensity of the somatic dimension ranged from 0.683 to 0.828 . The correlation coefficients between the intensity of each of the self-confidence dimension statements and the total score of the intensity of the self-confidence dimension ranged from 0.705 to 0.852 . All these values are statistically significant at the level of 0.01 , thus indicating the validity of internal consistency of the statements expressing the intensity of the sport competition anxiety.

It was also found that the correlation coefficients between the direction of each of the cognitive dimension statements and the total score of the direction of the cognitive dimension ranged from 0.657 to 0.853 . The correlation coefficients between the direction of each of the somatic dimension statements and 
the total score of the direction of the somatic dimension ranged from 0.677 to 0.856 . The correlation coefficients between the direction of each of the self-confidence dimension statements and the total score of the direction of the self-confidence dimension ranged from 0.637 to 0.759 . All these values are statistically significant at the level of 0.01 , thus indicating the validity of internal consistency of the statements expressing the direction of the sport competition anxiety

\section{Reliability Coefficient}

The reliability coefficient of the sport competition anxiety inventory was calculated by using Cronbach's coefficient alpha [Attachment $2]$, which showed high values of both intensity and direction, ranging from 0.728 to 0.856 . The inventory thus has reliability coefficients that are acceptable.

\section{The Basic Study:}

This study was conducted as follows:

First measurement in rest time (three weeks before the competition):

1. The measurement was conducted on Monday, $12 / 10 / 2009$ in the laboratory of faculty of physical education for boys, Alexandria University at 12.00 at after noon. The sample subjects were subjected to a preliminary medical examination by a general practitioner physician to make sure they were in good health, by measuring their blood pressure, pulse rate, temperature, lungs, and eyes. Height and weight of sample subjects were also measured and results were recorded on the form. Two members of the teaching staff in the faculty of physical education for girls, Alexandria University assisted in the measurement process after being informed of the research aims and how to measure and record results on the data form.

2. Distributing the sport competition anxiety inventory to the players with full explanation of instructions therein.

3. Physiological measurements were conducted (pulse rate/min. - breath rate /min).

4. The blood samples were collected by the laboratory technician, stored in sterilized tubes and kept in hand fridge so as to be carried to the laboratory where they would be analyzed.

Table (2)

Statistical description of the basic research sample data by the physiological variables, the concentration of Norepinephrine hormone in blood and the dimensions of the sports competition anxiety state in the first measurement (three weeks before the competition) $(N=6)$

\begin{tabular}{|c|c|c|c|c|c|c|c|}
\hline \multirow{2}{*}{\multicolumn{2}{|c|}{ Variables }} & \multirow{3}{*}{$\begin{array}{l}\mathbf{N} \\
6\end{array}$} & \multicolumn{5}{|c|}{ Descriptive Statistics } \\
\hline & & & \multirow{2}{*}{$\begin{array}{l}\text { Mean } \\
19.621\end{array}$} & \multirow{2}{*}{$\begin{array}{c}\text { Median } \\
19.5\end{array}$} & \multirow{2}{*}{$\begin{array}{c}\begin{array}{c}\text { Std. Error of } \\
\text { Mean }\end{array} \\
0.424 \\
\end{array}$} & \multirow{2}{*}{$\begin{array}{c}\begin{array}{c}\text { Std. } \\
\text { Deviation }\end{array} \\
1.467\end{array}$} & \multirow{2}{*}{$\begin{array}{r}\text { Skewness } \\
-0.108\end{array}$} \\
\hline & Breath rate/m & & & & & & \\
\hline Physiological & Pulse rate/m & 6 & 71.250 & 71.5 & 0.664 & 2.301 & 0.010 \\
\hline \multicolumn{2}{|c|}{$\begin{array}{l}\text { Level of Concentration of } \\
\text { Norepinephrine hormone }\end{array}$} & 6 & 0.423 & 0.42 & 0.031 & 0.107 & -0.601 \\
\hline \multirow{3}{*}{ Anxiety intensity } & Cognitive & 6 & 16.667 & 17 & 0.700 & 2.425 & -0.680 \\
\hline & somatic & 6 & 16.083 & 16 & 0.514 & 1.782 & -0.033 \\
\hline & $\begin{array}{c}\text { Self- } \\
\text { Confidence }\end{array}$ & 6 & 28.000 & 28 & 0.537 & 1.859 & -0.612 \\
\hline \multirow[b]{3}{*}{ Anxiety direction. } & Cognitive & 6 & 43.667 & 43.5 & 0.678 & 2.348 & 0.380 \\
\hline & somatic & 6 & 41.083 & 41 & 0.398 & 1.379 & -0.176 \\
\hline & $\begin{array}{c}\text { Self- } \\
\text { Confidence }\end{array}$ & 6 & 54.333 & 54 & 0.620 & 2.146 & 0.142 \\
\hline
\end{tabular}

Table (2) shows that the physiological changes and the concentration of Norepinephrine hormone in the blood and the dimensions of the sports competition anxiety state in the first measurement (three weeks before the competition, ranged from 0.680 to 0.380 , i.e. falling at $( \pm 3)$ and is near to zero. This proves the homogeneity of the sample members in these variables.

- The second measurement (1 hour before the match):

- This measurement was conducted on Tuesday 3/11/2009 in Ibrahim Moustafa Hall in 
Alexandria Stadium. The measurement was done individually an hour before the match; start times were obtained from the judge panel and from the toss records and the order of the matches. The measurement was done as follows:

- Distributing the sport competition anxiety state inventory;
- Conducting the physiological measurements;

- Collecting blood sample by the laboratory technician.

\section{Statistical Treatments :}

The arithmetic mean - standard deviation coefficient of skewness - median - Pearson's correlation coefficient -change rate $-(\mathrm{T})$ test of differences.

\section{Results Presentation and Discussion:}

Table (3)

Difference significance and change rate between the first measurement (3 weeks before the competition) and the second measurement (1 hour before the first match) in the research variables $(N=6)$

\begin{tabular}{|c|c|c|c|c|c|c|c|c|c|}
\hline \multirow{2}{*}{\multicolumn{2}{|c|}{ ariables }} & \multicolumn{2}{|c|}{$\begin{array}{l}3 \text { weeks before } \\
\text { competition }\end{array}$} & \multicolumn{2}{|c|}{$\begin{array}{l}1 \text { hour before } \\
\text { competition }\end{array}$} & \multicolumn{2}{|c|}{$\begin{array}{c}\text { Paired } \\
\text { Differences }\end{array}$} & \multirow[b]{2}{*}{$\mathbf{T}$} & \multirow{2}{*}{$\begin{array}{l}\text { Change } \\
\text { rate }\end{array}$} \\
\hline & & & & & & & & & \\
\hline \multirow{2}{*}{$\begin{array}{c}\text { Physiologic } \\
\text { al }\end{array}$} & $\begin{array}{l}\text { Breath } \\
\text { rate/m }\end{array}$ & $\begin{array}{c}19.62 \\
1\end{array}$ & 1.467 & 28.583 & 1.929 & 8.963 & 1.385 & $\begin{array}{c}22.425 \\
*\end{array}$ & 45.681 \\
\hline & Pulse rate/m & $\begin{array}{c}71.25 \\
0\end{array}$ & 2.301 & $\begin{array}{c}103.33 \\
3\end{array}$ & 4.519 & $\begin{array}{c}32.08 \\
3\end{array}$ & 5.854 & $\begin{array}{c}18.986 \\
*\end{array}$ & 45.029 \\
\hline \multicolumn{2}{|c|}{$\begin{array}{l}\text { Level of Concentration of } \\
\text { Norepinephrine hormone }\end{array}$} & 0.423 & 0.107 & 0.849 & 0.125 & 0.426 & 0.194 & $7.610^{*}$ & 100.709 \\
\hline \multirow{3}{*}{$\begin{array}{l}\text { Anxiety } \\
\text { intensity }\end{array}$} & Cognitive & $\begin{array}{c}16.66 \\
7\end{array}$ & 2.425 & 25.917 & 1.676 & 9.250 & 3.306 & $9.691 *$ & 55.499 \\
\hline & somatic & $\begin{array}{c}16.08 \\
3\end{array}$ & 1.782 & 21.083 & 1.929 & 5.000 & 2.892 & $5.989^{*}$ & 31.089 \\
\hline & $\begin{array}{c}\text { Self- } \\
\text { Confidence }\end{array}$ & $\begin{array}{c}28.00 \\
0\end{array}$ & 1.859 & 20.583 & 1.443 & 7.417 & 2.234 & $\begin{array}{c}11.499 \\
*\end{array}$ & 26.489 \\
\hline \multirow{3}{*}{$\begin{array}{l}\text { Anxiety } \\
\text { direction. }\end{array}$} & Cognitive & $\begin{array}{c}43.66 \\
7\end{array}$ & 2.348 & 34.833 & 2.552 & 8.833 & 3.589 & $8.527^{*}$ & 20.228 \\
\hline & somatic & $\begin{array}{c}41.08 \\
3\end{array}$ & 1.379 & 30.250 & 1.960 & $\begin{array}{c}10.83 \\
3\end{array}$ & 2.406 & $\begin{array}{c}15.599 \\
*\end{array}$ & 26.369 \\
\hline & $\begin{array}{c}\text { Self- } \\
\text { Confidence }\end{array}$ & $\begin{array}{c}54.33 \\
3\end{array}$ & 2.146 & 44.083 & 2.999 & $\begin{array}{c}10.25 \\
0\end{array}$ & 4.555 & $7.795^{*}$ & 18.865 \\
\hline
\end{tabular}

* Sig $0.05=2.360$ 
Figure (1)

The arithmetic mean in the first measurement (3 weeks before competition) and the second measurement (1 hour before first match) in research variables

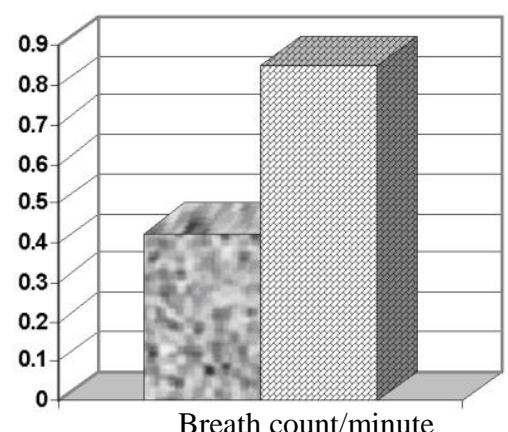

3 weeks before competition 1 hour before match

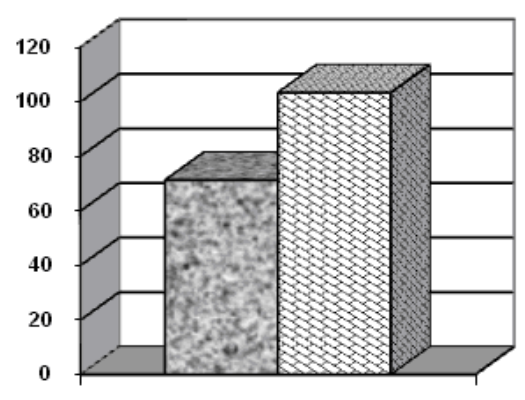

Pulse rate/minute

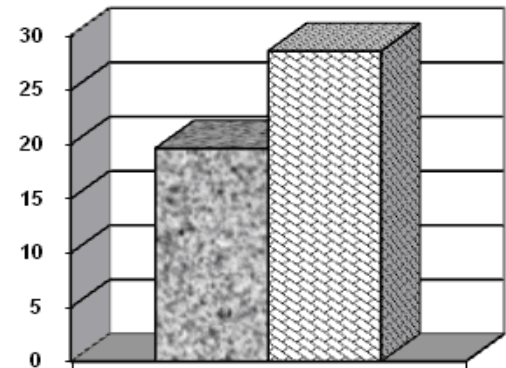

Norepinephrine concentration level in blood

ㄱ 3 weeks before competit图 1 hour before match

\section{Physiological and biochemical changes}

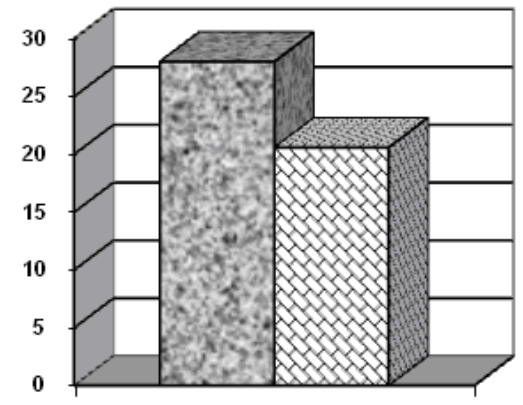

Cognitive

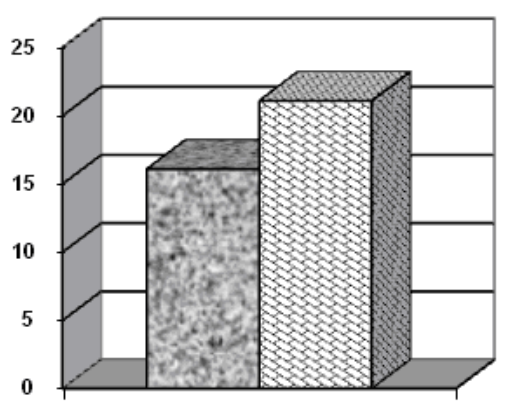

Physical

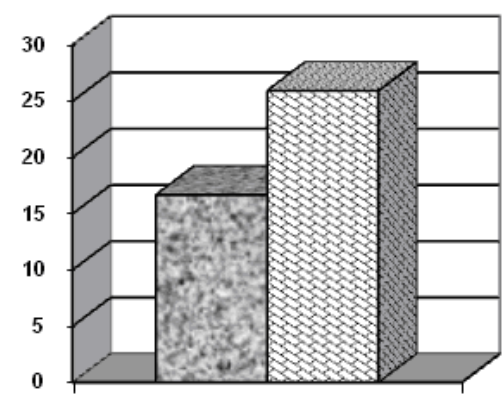

Self-confidence

口 3 weeks before compe圈on 1 hour before mat 4

口 3 weeks before competiti目 1 hour before match

口 3 weeks before competion 1 hour before match

\section{Intensity of sport competition anxiety}

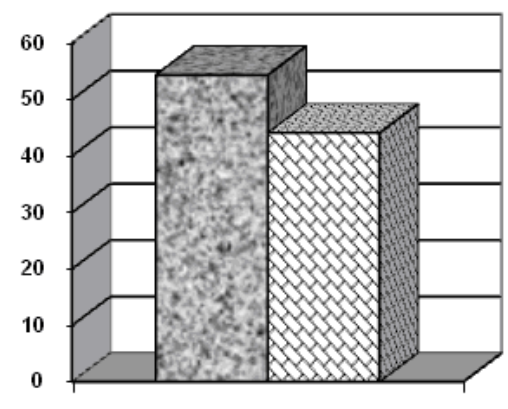

Cognitive

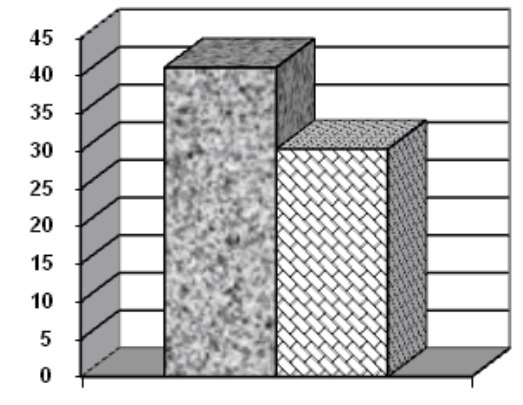

Physical

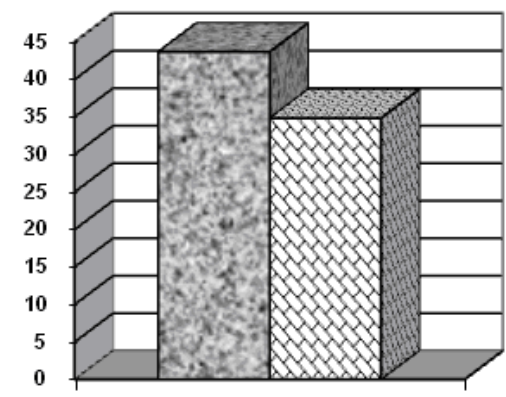

Self-confidence

$\square$ 3 weeks before competition $\square \quad 1$ hour before match

$\square 3$ weeks before competition 1 hour before match

\section{Direction of sport competition anxiety}


Table (3) and figure (1) show that there are statistically significant differences between the first measurement (3 weeks before the competition) and the second measurement, (1 hour before the first match) favoring the second measurement concerning breath rate, pulse rate and the concentration of Norepinephrine hormone in blood. The $(\mathrm{T})$ calculated values were $22.425,18.986$ and 100.709 , respectively. These values are higher than the tabular $\mathrm{T}$ value at the level 0.05 with a change rate of 45.681 , 45.029 and 100.709 .

There are also statistically significant differences between the two measurements favoring the second measurement in the intensity of cognitive anxiety and the intensity of somatic anxiety. The (T) calculated values were 9.691 and 5.989. These values are higher than the tabular $\mathrm{T}$ value at the level 0.05 with a change rate of 55.499 and 31.089. There are also statistically significant differences between the two measurements favoring the first measurement in the intensity of self-confidence, cognitive anxiety direction, intensity of somatic anxiety and the direction of self-confidence. The $\mathrm{T}$ calculated values were $11.499,8.527,15.599$ and 7.795 respectively. These values are higher than the tabular $\mathrm{T}$ value at the level 0.05 with a change rate of $26.489,20.228,26.369$ and 18.865 .

The rise in pulse rate per minute, breath rate and the concentration of Norepinephrine hormone in blood 1 hour before the first match was attributed to the intensity of anxiety undergone by the player which leads to the arousal of the sympathetic nervous system which sends signals to the adrenal gland marrow to release Norepinephrine hormone causing a rise in pulse rate and breath rate.

For a top level karate player, a match is of a great importance, as he is the only one who takes the consequences of the match and who is responsible for his behaviour. The competitive situation creates a state of anxiety caused by the fear of failure and the loss of social prestige associated with losing the game. This is suggested in the studies by Gold et. al. (1983)(22), stating that the most common source of anxiety among wrestlers is the fear of failure, lack of efficiency and social depreciation.
The rise of pulse rate and breath rate and the concentration level of Norepinephrine hormone confirms the close relationship between them, and that they are inseparable. Bahaa Eddin Salama confirms that the physiological and biochemical changes are inseparable and that they should be considered together, since they affect the other. Besides, knowing the chemical changes taking place in the body makes it easy to know the physiological changes and why they occur. (4:5)

Abdul Wahhab Kamel (1994) suggests that pulse rate rises during an intense anxiety state as a result of the signals sent to the heart from the sympathetic nervous system, thus increasing the activity of the heart and the number of heartbeats, affected in that by the activity of the Hipthalams and the Limbic System. He, also, says that persons who show a higher degree of anxiety, also show a high breath rate compared to those who have an average or low degree of anxiety in the pressing emotional situations. (8 : 251, 252)

The results of this study are consistent with those of the study by Lundberg and Forsman (1980) (28), who proved the positive correlation between the release of Norepinephrine hormone and the pulse rate. As more Norepinephrine hormone is released in blood, the functional rates of work of the heart increase and are reflected in the pulse rate.

This result is also in conformity with results of the study by Pillat et. al. (1999)(30) who suggested that the secretion rate of Norepinephrine hormone relatively increases in emergency situations, especially when one is emotionally excited. The hormone is released in small amounts which increase as the emotional situation intensifies.

According to Fathy Abdul Rahman (2000) (10), practicing boxing increases the concentration level of Norepinephrine hormone in blood.

The study of Vigas et.al. (1998) (32) found that athletes with a high fitness profile have a higher rate of the Norepinephrine plazma in the blood.

Higher intensity of somatic anxiety and higher intensity of cognitive anxiety lead to a lower intensity of self-confidence before competition. This is reflected on the direction of anxiety (i.e. it becomes more retarding), and this is clear in 
the decline of values of the cognitive, somatic and self-confidence directions.

Cox (1985) suggests that top level wrestlers show high level of anxiety that increases before the competition whereas self-confidence decreases.(19:88)

Abdul Aziz Salama (2001) suggests that the combat player may have a strong feeling that he is not able to control the competition events, and that they are not going on as he planned, causing him to feel anxious and causing anxiety symptoms to appear. $(15: 208)$

This result is consistent with the results of the study by Terry et. al. (1996) (31), suggesting that single tennis players show a higher degree of intensity of cognitive and somatic anxiety, and a lower degree of self-confidence compared to double tennis players.

This is also consistent with results of the study by Gold et.al. (1983) (21) who found that somatic anxiety and cognitive anxiety grow higher among high level wrestlers when competition is imminent. It also agrees with findings of the study by Kim (2009) (26) who found that somatic anxiety is higher in distinguished golfers before competition than after it.

Mckay's study (1997) (29) found that high-level golfers are characterized by intensity of cognitive and somatic anxiety before competition and, consequently, lower selfconfidence level. The study of Filaire et. al. (2001) (20) also found that judo players showed high cognitive and somatic anxiety with low self-confidence before the first match.

Hanton's study (2004) (24) found out a rise in the cognitive and somatic anxiety and a decline of self-confidence in the period between two hours and half an hour before the competition.

This proves that, the first hypothesis in the present study is achieved:

There are statistically significant differences between the first measurement ( 3 weeks before the competition); and the second measurement ( 1 hour before the first match) in karate players in the dimensions of the start anxiety state (intensity - direction) and the physiological changes (pulse rate - breath rate) and the concentration level of Norepinephrine hormone in blood .

Table (4)

Correlation coefficients between the physiological variables, the concentration level of Norepinephrine hormone in blood and the dimensions of sport competition anxiety (1 hour before the first match). $(N=6)$

\begin{tabular}{|c|c|c|c|c|c|c|}
\hline \multirow{2}{*}{ Correlations } & \multicolumn{3}{|c|}{ Intensity of anxiety } & \multicolumn{3}{c|}{ Direction of anxiety } \\
\cline { 2 - 7 } & Cognitive & Somatic & $\begin{array}{c}\text { Self- } \\
\text { confidence }\end{array}$ & Cognitive & somatic & $\begin{array}{c}\text { Self- } \\
\text { confidence }\end{array}$ \\
\hline Breath rate/min. & -0.574 & 0.259 & -0.133 & -0.479 & -0.475 & -0.103 \\
\hline Pulse rate/min. & -0.482 & -0.275 & -0.116 & 0.273 & -0.072 & 0.058 \\
\hline $\begin{array}{c}\text { Concentration of } \\
\text { norepinephrine in } \\
\text { blood }\end{array}$ & 0.391 & 0.413 & -0.473 & -0.540 & -0.453 & -0.407 \\
\hline
\end{tabular}

\section{Correlations sig $0.05=0.754$}

Table (4) shows no correlation between the physiological changes, the Norepinephrine hormone in blood, and the dimensions of sport competition anxiety state 1 hour before the first match.

This result is attributed to the lack of sincerity from the subject when answering the inventory question about how he actually feels before competition regarding the physiological changes. This gives an incorrect significance of the anxiety state of the player, whereas the physiological and hormonal changes are measured objectively using scientific devices that give the correct significance of the changes in the player 1 hour before the competition as a result of the start anxiety state.

This result is again consistent with the study of Filaire et. al. (2001) (20), who found that there was no relationship between hormonal response and the components of anxiety (cognitive and somatic anxiety), and with the study of Karteroliotis and Gill (1987) (25) who found that there were no statistically significant relationship between the results of physiological measurements (pulse rate) and the results of sports competition anxiety inventory of the 
high-skilled players in physical education schools. It is also consistent with the study of Loupos et. al. (2008) (27) who found that there were no correlation between the psychological measurements (cognitive anxiety - somatic anxiety) and the physiological measurements (level of Cortisol - blood pressure, systolic and diastolic blood pressure - pulse rate) of swimmers before competition.

This proves that, the second hypothesis in the present study didn't achieve.

\section{Conclusions:}

1. There was an increase in the intensity of cognitive and somatic anxiety of karate players 1 hour before the competition, and a decrease of cognitive, somatic directions 1 hour before competition.

2. Self-confidence of karate players decreased 1 hour before competition.

3. There was an increase in the Norepinephrine hormone secretion in blood 1 hour before competition, with the amount released twice as high as in the normal condition 3 weeks before competition.

4. There was no relationship between the dimensions of the sports competition anxiety state and the physiological variables and the rate of the Norepinephrine hormone secretion in blood.

5. Intensity of cognitive anxiety was higher than intensity of somatic anxiety in karate players 1 hour before competition.

\section{Recommendations:}

1. Relying less on 'pen and paper' tests in identifying the players' anxiety before sports competitions, and more on the physiological and biochemical measurements, if possible, to give precise evidence on the start anxiety state.

2. Developing physiological and biochemical indicators to identify the start anxiety state in karate players.

3. Developing strategies of cognitive intervention for karate players to reduce the intensity of cognitive anxiety they feel before competition.

\section{References:}

1. Ahmed Amin Fawzi (2003): Principles of Sport Psychology - Concepts - Applications 1st edition, Dar El-Fikr El-Araby.

2. Ahmed Okasha (1993): Physiological psychology, 2nd edition,Al-Anglo Egyptian Bookshop.

3. Osama Kamel Rateb (2000): The Psychology of Sport, 3rd edition, Dar El-Fikr El-Araby.

4. Bahaa Eddin Ibrahim Salama (1990): BioChemistry in Sport, Dar El-Fikr El-Araby.

5. Bahaa Eddin Ibrahim Salama (1994): Sport Physiology, 2nd edition, Dar El-Fikr El-Araby Cairo.

6. Abdel Rahman Adas, Mohiy Eddin Tok (1992): Introduction to Psychology, 4th edition, Dar El-Fikr Publication and Distribution House.

7. Abdel Mottaleb Amin Al-Quraity (1998): On Psychological Well Being, Dar El-Fikr El-Araby.

8. Abdel Wahab Mohamed Kamel (1994): Pysiological Psychology - introduction to psychphysiological and Neurological Foundations of Human Behaviour, 2nd edition, Al-Nahda Egyptian Bookshop.

9. Ghada Mohamed Abdel Hamid (2003): A Study of the Concentration Level of Adrinalin and Noradrinalin in Blood after a $100 \mathrm{~m}$ Sprint and its Relationship to the Physical Efficiency Level. Nazaryat Wa Tatbiqat, Faculty of Physical Education for Boys, Alexandria University, No 47.

10. Fathy Abdel Rahman Aly (2000): The Effect of Loads of Different Intensity on Some Blood Hormones in Some Boxers, unpublished Ph. D. Dissertation, faculty of Physical Education, Tanta University.

11. Mohamed Hassan Allawy (1998): Encyclopedia of Psychological Tests, 1st Edition, Markaz El-Kitab Publication House.

12. Mohamed Hassan Allawy (1998): Introduction to Sport Psychology1st Edition, Markaz El-Kitab Publication House.

13. Mohamed Hilmy, Gamal Eddin Abdel Rahim, Farahat El-Desouky (2001): Hormones and Endocrines, Monshaat El-Maaref, Alexandria.

14. Mohamed Samir Saad Eddin (2000): Physiology and The Physical Effort, 3rd edition Monshaat ElMaaref, Alexandria.

15. Mohamed Abdel Aziz Salama (2001): Concepts in the Psychology of Sport Competition, 1st edition, Dar El-Gameyyeen Printing house, Alexandria. 
16. Mahmoud Abdel Fattah Anan (1995): Psychology of Physical Education and Sport, The Theory, Application and Experimentation, 1st edition Dar El-Fikr Al-Araby.

17. Mosaad Aly Mahmoud (2001): The Basic Foundations of Roman and Free StyleWrestling, 2nd edition, Dar El-Tebaa Publication and Distribution House, Mansoura.

18. Mostafa Hussein Bahi, Hussein Ahmed Heshmat and Nabil El-Sayed Hassan (2002): A Reference Book in Physiological Psychology - Theories, Analises, Applications, Al-Anglo Egyptian Bookshop.

19. Cox, R., (1985): Sport psychology concepts and applications, wm. C. Brown Publishers.

20. Filaire, E., Sangol, M., Ferrand, C., Maso, F., and Jac, D., (2001): Psycho physiological stress in judo athletes during competition, Journal of sport medicine and physical fitness, Jun., Vol., 41, No., 2.

21. Gold, D., Petlichkpff, L., and Weinberg, R., (1983): Competitive anxiety in junior elite wrestlers, Journal of sport psychology, Vol., 5, No. 1.

22. Gould, D., Thalma, C., and Jaine, A., (1983): Sources of stress in junior elite wrestlers, Journal of sport psychology, Vol., 5, No., 3.

23. Guyton, C., (1986): Textbook of medical physiology W. B. Saunders company.

24. Hanton, S., Thomas, O., Maynard, I., (2004): Competitive anxiety responses in the week leader up to competition: the role of intensity, direction and frequency dimensions, psychology of sport and exercise, Vol., 5.

25. Karteroliotis, C., and Gill, D., (1987): Temporal changes in psychological and physiological components of state anxiety, Journal of sport psychology, Vol., 9, No., 3.

26. Kim, K., Chung, J., Park, S., Shin, J., (2009): Psycho physiological stress response during competition between elite and non - elite Korean junior golfers, international journal of sport medicine, July, Vol., 30. No., 7.

27. Loupos, D., Fotini, M., Barkoukis, V., Tsorbatzou'dis, H., Grouios, G., and Taitzoglou, I., (2008): Psychological and physiological changes of anxiety prior a swimming competition, the open sports medicine journal, Vol., 2.

28. Lundberg, U., and Forman, L., (1980): Consistency and cortisol excretion patterns over experimental conditions. Parmacol Biochemical behavior, March, Vol., 12, No., 3.

29. McKay, J., Selig, S., Carlson, J., and Morris, T., (1997): Psycho physiological stress in elite golfers during practice and competitive, Australian journal, Jun., Vol., 29, No., 2.

30. Pillat, V., Flechet, B., Petiti, B., Muriaux, G., and Koralsztein, J., (1999): Interval training at vo2 max: effects on aerobic performance and over training markers, medicine, and science in sports and exercise, Jan Vol., 31, No., 1.

31. Terry, P., Cox., J., Jan, A., and Karageoraghis, C., (1996): Measure of anxiety among tennis players in singles and jouble matches, perceptual motor skill, Oct., Vol., 83, No., 2.

32. Vigas, M., Celko, Jurankova, E., Jegova, D., and Dvetnasky, R., (1998): Plasma catecholamine and renin activity in wrestlers following vigorous swimming, physiological research, Vol., 47, No. 3. 